Antonio Marcos ORSI ${ }^{1}$

Karina SIMÕES ${ }^{2}$

Márcia Rita Fernandes

$\mathrm{MACHADO}^{3}$

Raquel Fantin

DOMENICONI ${ }^{4}$

Correspondência para:

Antonio Marcos Orsi, Departamento de Anatomia-UNESP, CXP. 510, 18602-170 Botucatu, SP, Brasil, amorsi@ibb.unesp.br

Recebido para publicação: 05/02/2009 Aprovado para publicação: 27/08/2009

\title{
Características regionais sobre a ultra-estrutura das células principais do epitélio do ducto epididimal de Agouti paca
}

\author{
1 - Departamento de Anatomia da Universidade Estadual Paulista, Botucatu-SP \\ 2 - Setor de Anatomia do Centro Universitário de Rio Preto, São José do Rio \\ Preto-SP \\ 3 - Departamento de Morfologia e Fisiologia Animal da Universidade Estadual \\ Paulista, Jaboticabal-SP \\ 4 - Departamento de Anatomia da Faculdade de Medicina de Marília, Marília-SP
}

\section{Resumo}

As células principais $(\mathrm{P})$ do epitélio de revestimento do epidídimo de paca foram relacionadas com processos citofisiológicos de endocitoses do tipo adsortiva e de fase fluida, respectivamente, aparentemente realizando também secreção apócrina. Essas funções foram propostas embasando-se em características de ultra-estrutura das células P, em cujos citoplasma observaram-se um expressivo número de vesículas, com diferentes formas, tamanhos e presença de conteúdo internalizado em algumas das vesículas revestidas por endomembranas, ocorrendo ainda caveolas e vesículas diminutas localizadas junto à borda apical de microvilos. Ademais, observaramse vesículas grandes e revestidas e/ou com superfícies lisas; endossomos, e lisossomos de localização predominantemente apical. Uma via de secreção apócrina foi sugerida com base na ocorrência de expansões (protrusões), citoplasmáticas intraluminais nas células P.
Palavras-chave: Epitélio epididimal. Células principais. Ultra-estrutura. Agouti paca.

\section{Introdução}

Os principais tipos celulares presentes no epitélio epididimal de mamíferos são as células principais $(\mathrm{P})$, cujas principais funções foram descritas como endocitose adsortiva, e, endocitose de fase fluida, reabsorção do fluido luminal, secreção de proteínas e secreção de glicoproteínas; trocas de água, íons salinos e macromoléculas ocorrendo entre os compartimentos epididimais epitelial e luminal, respectivamente. ,2,3,4,5,6,7,8 $^{-}$

A habilidade das células $\mathrm{P}$ para secretar proteínas, inclusive glicoproteínas ${ }^{4}$, tem sido relacionada com o seu bem desenvolvido "sistema organelar" associado à síntese e secreção, tal como a presença de um marcante retículo endoplasmático rugoso (RER) associado com o aparelho reticular de Golgi 6,7,8,9. Ocorrem também outras formações ultraestruturais relacionadas diretamente ao complexo
RER-Golgi ${ }^{5}$, tais como as vesículas escuras e revestidas, vesículas de exocitose e talvez de transcitose, que foram similarmente observadas no próprio epidídimo ${ }^{5,6,7,8}$, assim como em células cilíndricas do epitélio de revestimento dos ductos eferentes de alguns mamíferos $^{10}$.

O emprego de marcadores de macromoléculas, colocados no microambiente epididimal, foi útil para demonstrar o transporte e a incorporação de aminoácidos livres através da superfície livre das células epiteliais, principalmente em células $\mathrm{P}$ epididimais., Adicionalmente, uma via secretória intracitoplasmática de proteínas foi demonstrada em células P epididimárias de camundongos por Flickinger ${ }^{4}$. Outros papéis funcionais, menos usuais, foram caracterizados em células $\mathrm{P}$ epididimais de mamíferos, bem como em outros segmentos da via espermática, tais como a ocorrência de espermiofagia ${ }^{5,11}$, e, a presença 
de expansões citoplasmáticas apicais, com significado de possível secreção celular apócrina, notada em células $\mathrm{P}^{12,13,14}$.

Tendo em vista o suporte de literatura exposto, neste estudo fez-se uma análise da ultraestrutura do epitélio de revestimento do ducto epididimário de paca adulta, o segundo maior roedor da região neotropical, após a capivara, tendo grande potencial zootécnico. Isso porque a sua carne é muito apreciada para consumo humano ${ }^{15}$. Ainda, segundo Eisenberg ${ }^{16}$, a paca pertence à família Agoutidae, gênero Agouti, que juntamente com as famílias Caviidae, Hydrochoeridae e Dasyproctidae constituem o grupo dos roedores Histricognatas do Novo Mundo.

\section{Material e Método}

Fragmentos de tecidos coletadas dos epidídimos de seis pacas Agouti paca, machos e adultas, foram fixados em solução de glutaraldeído a 2,5\% em

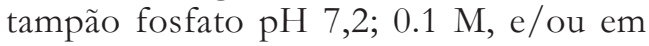
fixador de Karnovsky, durante 3 horas a $4^{\circ} \mathrm{C}$. Em seqüência os materiais, após conveniente redução e identificação regional das porções denominadas de segmento inicial, cabeça, parte média do corpo e parte distal da cauda dos epidídimos foram pós-fixados em $\mathrm{OsO}_{4}$ no mesmo tampão. Adotou-se o mesmo modelo de histologia regional do epidídimo proposto, previamente, para o rato marrom ${ }^{7}$.

Após a finalização da fixação tecidual, seguiu-se a desidratação dos materiais em série crescente de acetona, inclusão em Araldite (Merck, Alemanha), "trimagem" dos blocos e obtenção de cortes semifinos $(0,5 \mathrm{~mm})$, e de cortes ultrafinos (80 nm em média). Montados em grades de cobre e contrastados com acetato de uranila e citrato de chumbo, os cortes ultrafinos foram analisados e fotografados em microscópio eletrônico de transmissão Philips CEM-100 (Philips, Holanda).

\section{Resultados}

No segmento inicial (SI) do epidídimo de Agoutipaca, as células principais (P), na superfície epitelial do revestimento tubular, mostraram, no citoplasma supranuclear, o retículo endoplasmático rugoso (RER), bem desenvolvido e formado por lamelas longas com disposições retilínea ou curvilínea. As lamelas apareceram dilatadas em suas extremidades e por vezes em suas partes médias, tendo grande quantidade de ribossomos aderidos às suas paredes, e agregados adjacentes de ribossomos livres formando polissomos (Figura 1). Verificaram-se algumas lamelas vesiculares do RER, que representavam cisternas muito dilatadas deste complexo reticular, tendo menor quantidade relativa de ribossomos aderidos. Lamelas vesiculares coexistiam com as lamelas alongadas do próprio RE e com os dictiossomos dos complexos de Golgi, abundantes e igualmente bem desenvolvidos, ao nível citoplasmático supranuclear. No conteúdo citoplasmático circunjacente às lamelas longas do RE, e aos sáculos do Golgi, se observou uma grande quantidade de vesículas com formas e conteúdos variados, e apareceram vesículas revestidas por endomebranas, tendo conteúdos claro, ou mais eletropaco, respectivamente, e também vesículas pálidas e de superfície lisa (Figura 2).

Em algumas células P do SI, junto à borda apical de microvilos, observaram-se cavéolas formadas na membrana citoplasmática apical, sendo que algumas delas se invaginavam para o citoplasma apical, no qual formavam vesículas pálidas caracterizando-se um processo de endocitose. Microtúbulos do sistema T apical foram evidentes, assim como complexos juncionais se formaram entre as membranas plasmáticas laterais de células $\mathrm{P}$ adjacentes, em nível apical (Figura 3). Ainda no citoplasma supranuclear de várias células $P$, do segmento inicial, observaram-se corpos multivesiculares complexos, englobando corpos densos de diferentes eletrodensidades, e material fragmentar (Figura 4), 

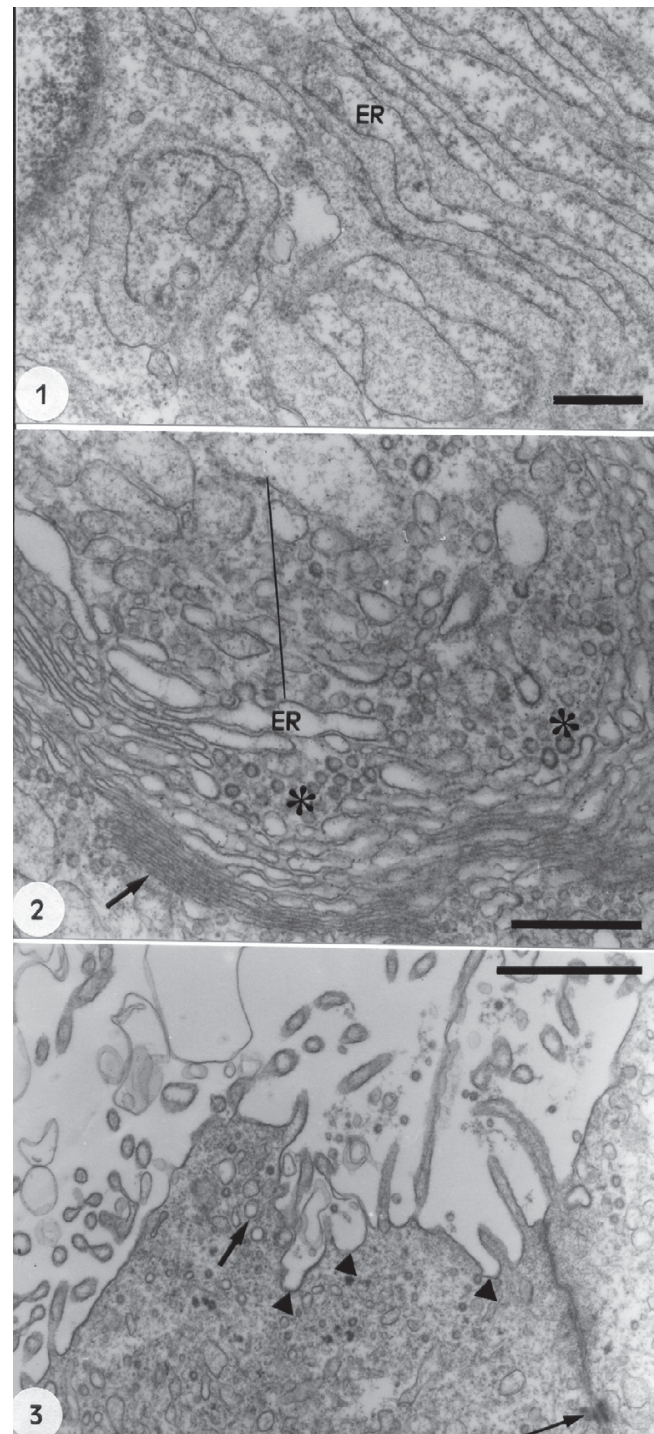

Figuras 1-3 - Ultraestrutura do citoplasma supranuclear de células $\mathrm{P}$ do SI epididimário de paca mostrando grande desenvolvimento do RER lamelar em 1; RER vesicular e lamelar (ER) com dictiossomos do Golgi (seta) e várias vesículas (asteriscos) de formas e tamanhos variados em 2; cavéolas (cabeças de seta), vesículas de endocitose (seta pequena) e complexos juncionais (seta fina) em 3. Bars $=0,5 \mu \mathrm{m}$ em 1, 2 . Bar $=1 \mu \mathrm{m}$ em 3

aparentemente, remanescente de organelas lisadas (autofagocitose). Porém, não se excluiria também a possibilidade de ocorrência de digestão heterofágica, feitas com apoio na observação, concomitante, de corpos densos homogêneos, de diferentes eletrodensidades (Figura 5), talvez se caracterizando-se

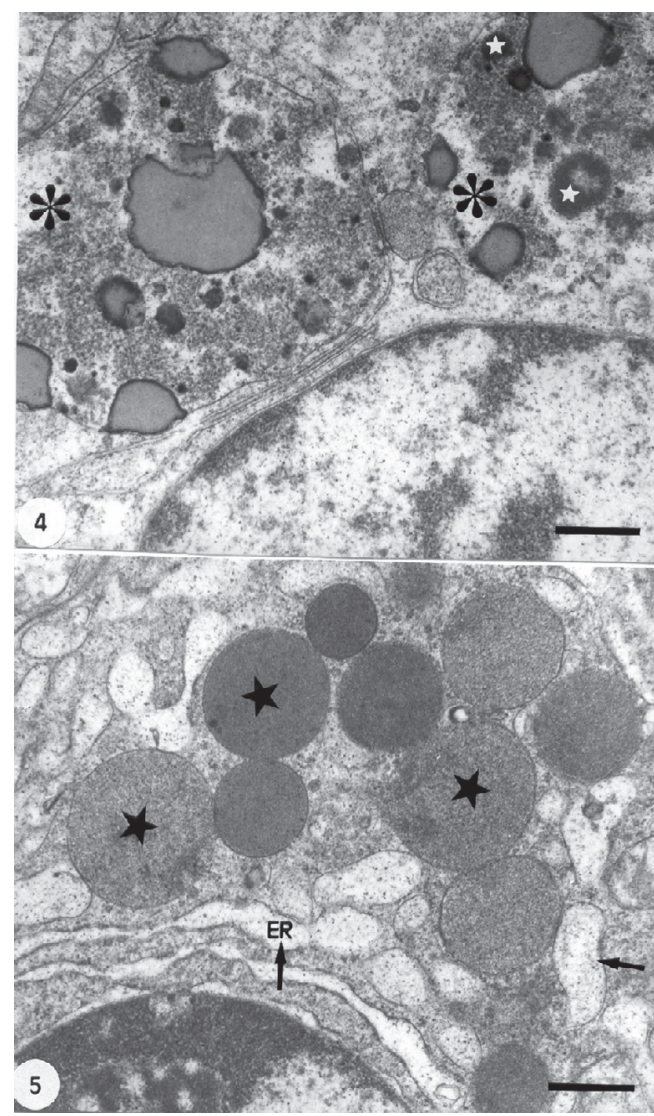

Figuras 4-5 - Citoplasma supranuclear de célula P no S sendo indicados corpos multivesiculares heterogêneos (asteriscos), lisossomos (estrelas) em 4, 5 e cisternas do RER (ER) em 5 . Bars $=0,5 \mu \mathrm{m}$

como lisossomos secundários com base comparativa. ${ }^{17}$

No citoplasma de células $\mathrm{P}$ da cabeça do epidídimo de paca, em diferentes níveis, observou-se grande quantidade de lisossomos (Figuras 6 a 8), observando-se também vesículas pálidas e um agregado de vesículas densas e revestidas (Figura 6). Adjacentes aos lisossomos, ocorriam lamelas alongadas do RER, polissomos, mitocôndrias, vesículas pequenas e revestidas e presença de corpo multivesicular pálido (Figura 7). Cisternas vesiculares adensadas do RER foram vistas no citoplasma supranuclear de algumas células $\mathrm{P}$, aparentemente circunscrevendo partes do conteúdo citoplasmático; tendo ribossomos aderidos às suas paredes externas (Figura 8).

$\mathrm{Na}$ parte média do corpo epididimal, o citoplasma supranuclear de várias células $\mathrm{P}$ 


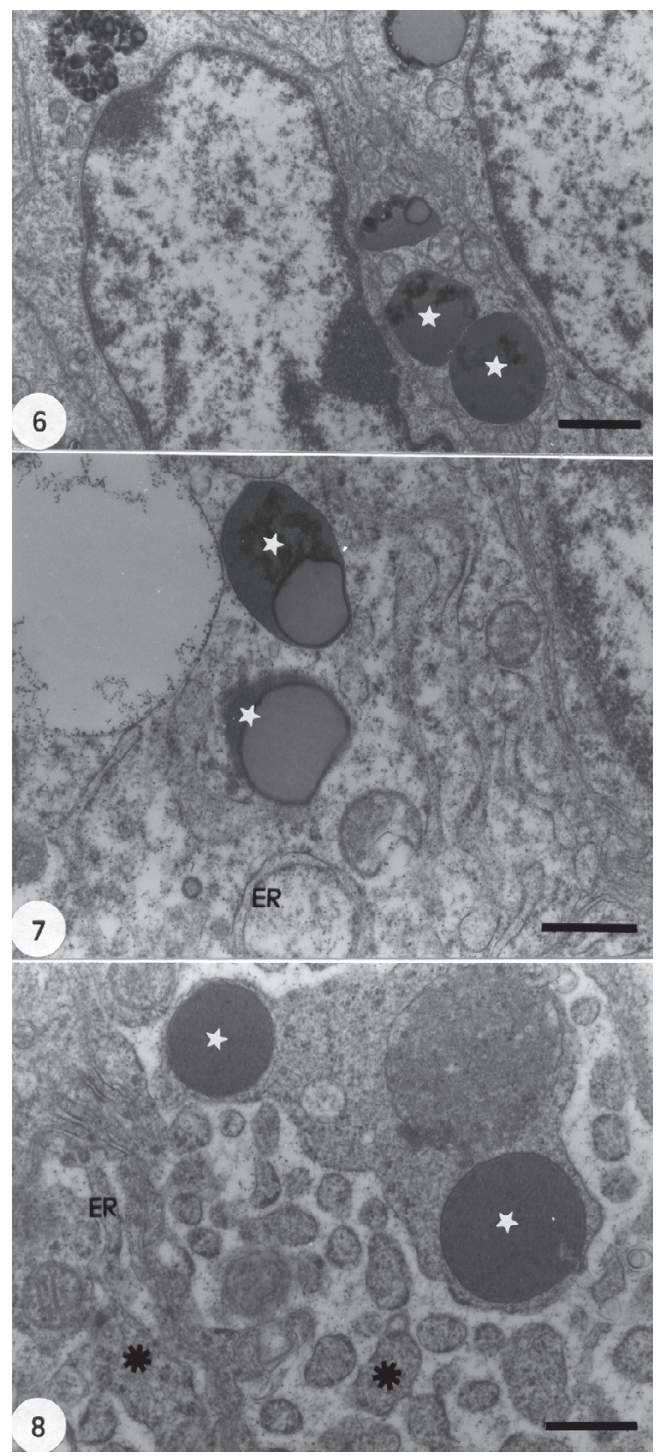

Figuras 6-8 - Ultraestrutura de células $P$ na cabeça epididimária de paca, sendo mostrados lisossomos (estrelas) em diferentes níveis citoplasmáticos, grande desenvolvimento do RER (ER) com cisternas vesiculares e adensadas (rosetas). Bar $=1 \mu \mathrm{m}$ em 6 Bars $=0,5 \mu \mathrm{m}$ em 7,8

foi caracterizado pela ocorrência de grande reticulação derivada do abundante RER, e por apreciável quantidade de lisossomos e de vesículas revestidas (Figuras 9e 10). As lamelas do RE apareceram predominantemente alongadas, sendo algumas delas dilatadas e com características vesiculares, evidenciandose também os dictiossomos do complexo de Golgi (Figura 10). Os lisossomos supranucleares eram precedidos por grande quantidade de endossomos, presentes no citoplasma apical das células P (Figura 11). Características subcelulares de endocitose, talvez predominantemente de fase fluida, foram observadas no citoplasma apical de células $\mathrm{P}$, onde se observaram cavéolas apicais, englobamento de vesículas pálidas na borda apical de microvilos, seguida pela presença de vesículas pálidas e presenças de endossomos e corpos multivesiculares, sendo estes predominantemente pálidos (Figuras 11 e 12). Junto à borda citoplasmática apical de algumas células $\mathrm{P}$, no corpo epididimal, observaram-se secções, com diferentes orientações, de partes estruturais de espermatozóides estocados na luz tubular, algumas delas fazendo contactos íntimos com a borda apical de microvilos, e/ou com a membrana plasmática de expansões citoplasmáticas apicais (Figuras 13 e 14). Tais expansões apresentavam lamelas concêntricas do RE em seu interior, predominando uma disposição circunferencial (Figura 14). Lamelas do RE, com disposição circunferencial, localizadas ao nível basal, delimitavam um espaço do conteúdo citoplasmático, no qual ocorriam mitocôndrias, formações vesiculares de dupla membrana, com um ou dois grânulos densos circunscritos por lamelas (Figura 15).

$\mathrm{Na}$ cauda epididimal de paca, o epitélio de revestimento era formado, predominantemente, por células P (Figuras 16 e 17). O citoplasma supranuclear, nestas células, apresentou grande concentração de lisossomos muito eletrodensos, cisternas lamelares do RE e muitas vesículas, predominantemente pequenas, mas variadas em forma e conteúdo (Figura 16). Cavéolas eram evidentes na membrana plasmática apical, sendo algumas delas internalizadas como vesículas revestidas, pequenas e claras, junto à borda citoplasmática subjacente (Figura 17).

Algumas poucas células $P$, na cauda epididimal, mostraram expansões citoplasmáticas apicais, projetando-se na 

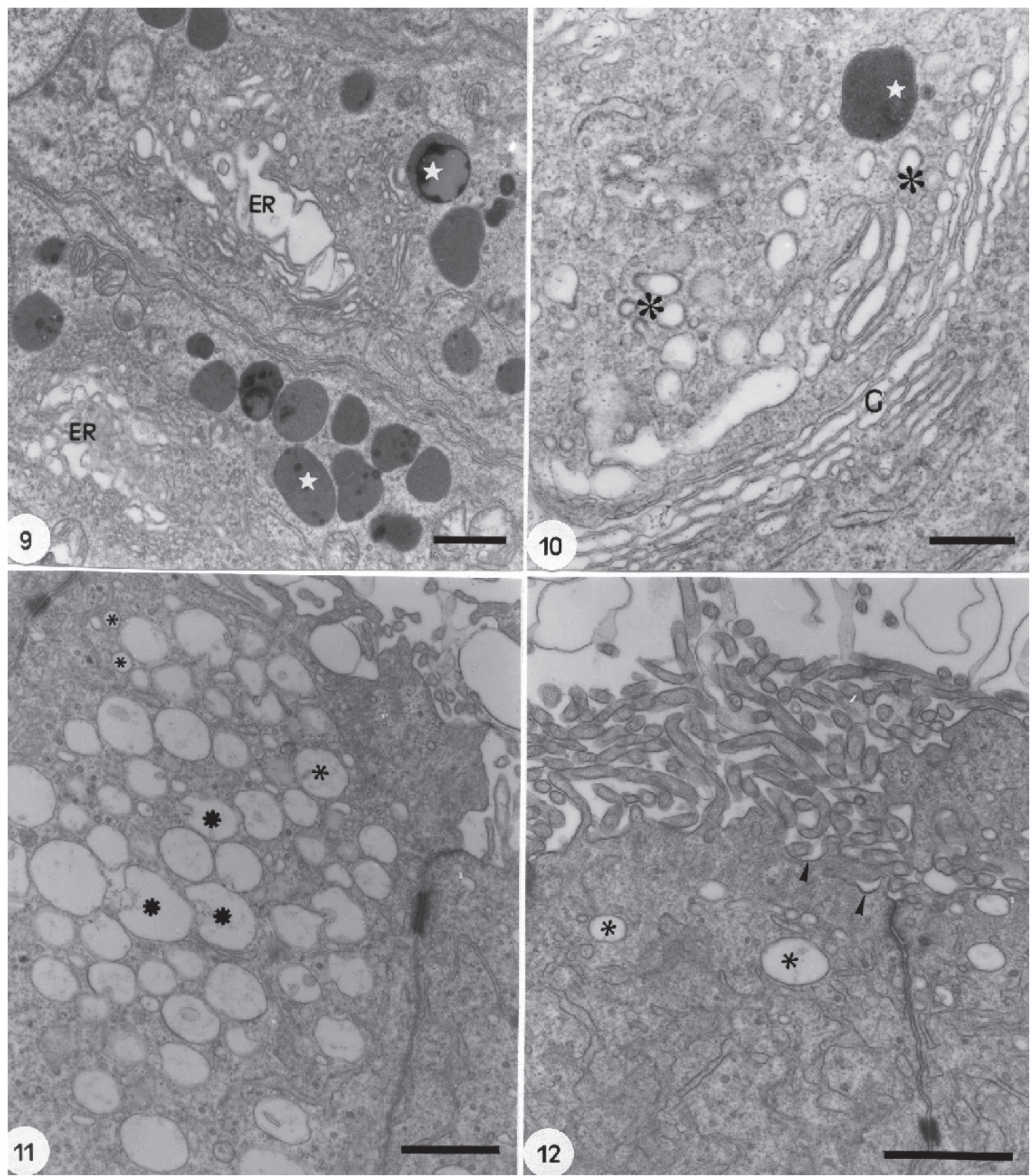

Figuras 9-12 - Citoplasma supranuclear de células P do corpo epididimário de paca mostrando grande desenvolvimento do RER (ER), complexo de Golgi (G), lisossomos (estrelas) em 9, 10 e várias vesículas pequenas densas e revestidas (asteriscos) em 10. Citoplasma apical de células P em 11 e 12 mostrando vesículas claras de endocitose (asteriscos), cavéolas (cabeças de seta) e endossomos (rosetas. Bars $=1 \mu \mathrm{m}$ em 9, 11 e 12. Bar $=0,5 \mu \mathrm{m}$ em 10

luz tubular entre a borda apical de microvilos, notando-se um grande grânulo de inclusão lipídica no conteúdo citoplasmático (Figura 18). No citoplasma infranuclear, de algumas células $\mathrm{P}$ da cauda epididimal, o RER apareceu circunferencial, com suas lamelas dispondo-se de forma concêntrica e paralelas entre si, delimitando uma parte homogênea e mais densa do conteúdo citoplasmático. Lamelas semicirculares do próprio RE apareceram adjacentes à formação circunferencial visualizada, sendo que uma delas contatava o envelope nuclear e a outra envolvia um lisossomo, com eletrodensidade heterogênea (Figura 19). 

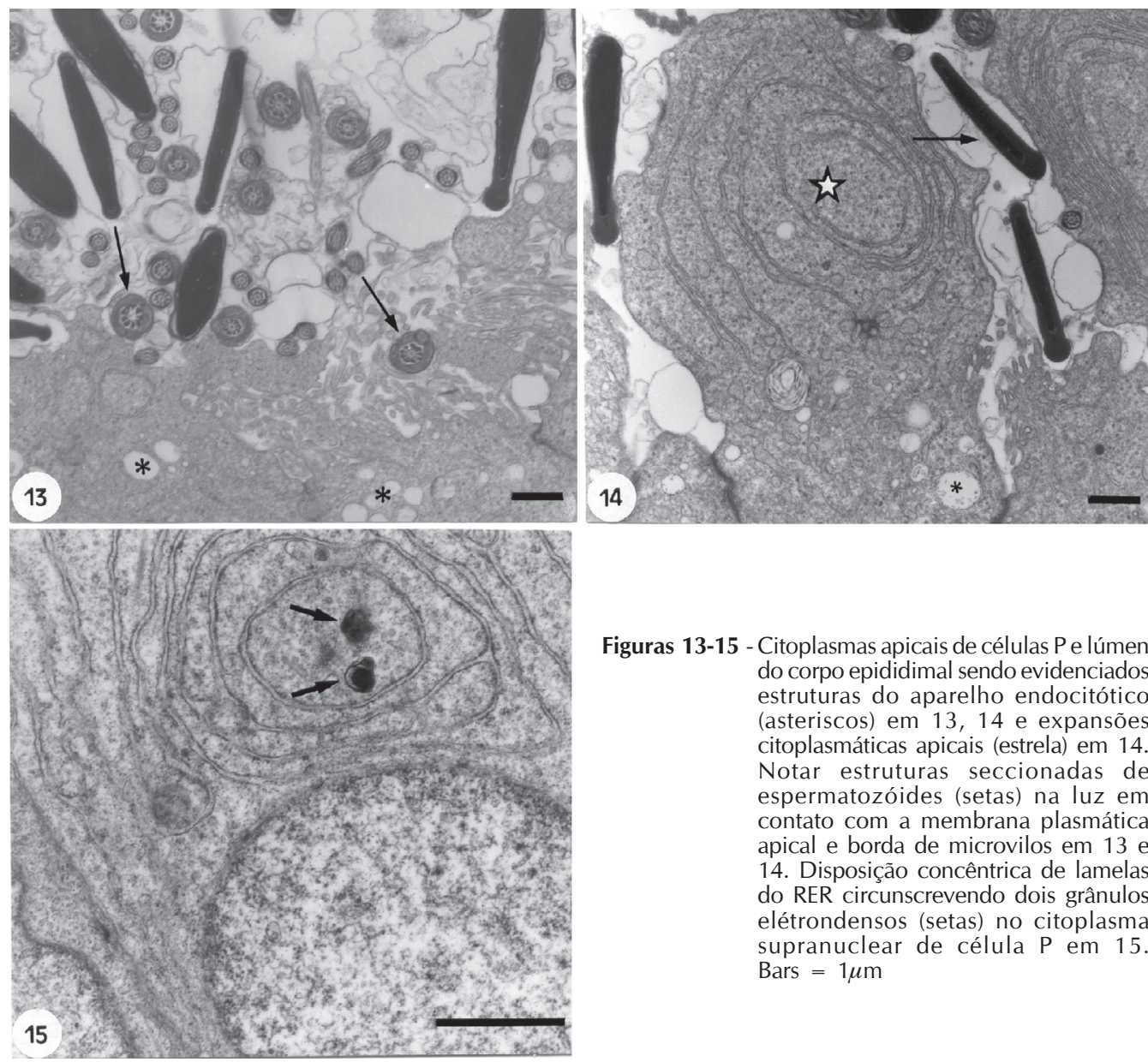

Figuras 13-15 - Citoplasmas apicais de células P e lúmen do corpo epididimal sendo evidenciados estruturas do aparelho endocitótico (asteriscos) em 13, 14 e expansões citoplasmáticas apicais (estrela) em 14 Notar estruturas seccionadas de espermatozóides (setas) na luz em contato com a membrana plasmática apical e borda de microvilos em 13 e 14. Disposição concêntrica de lamelas do RER circunscrevendo dois grânulos elétrondensos (setas) no citoplasma supranuclear de célula $\mathrm{P}$ em 15. Bars $=1 \mu \mathrm{m}$
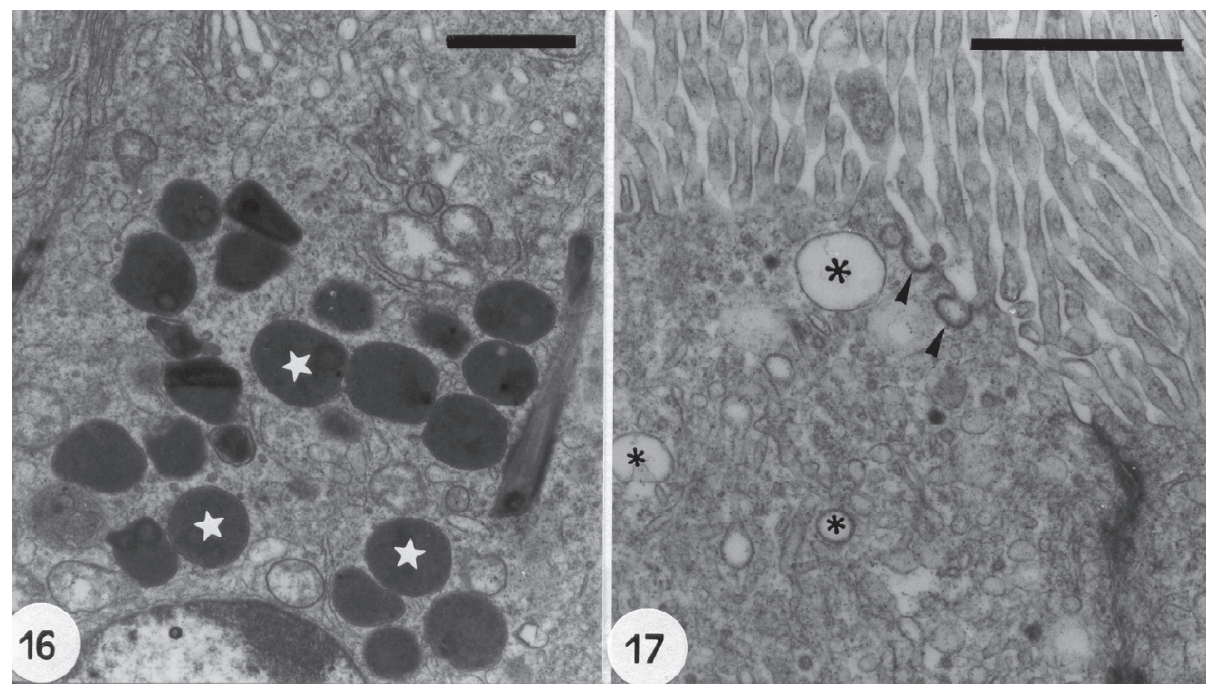

Figuras 16-17 - Citoplasma supranuclear e apical de células P da cauda epididimária de paca sendo evidentes lisossomos (estrelas) em 16; cavéolas (cabeças de seta), vesículas de endocitose e endossomo (asteriscos) em 17. Bars $=1 \mu \mathrm{m}$ 


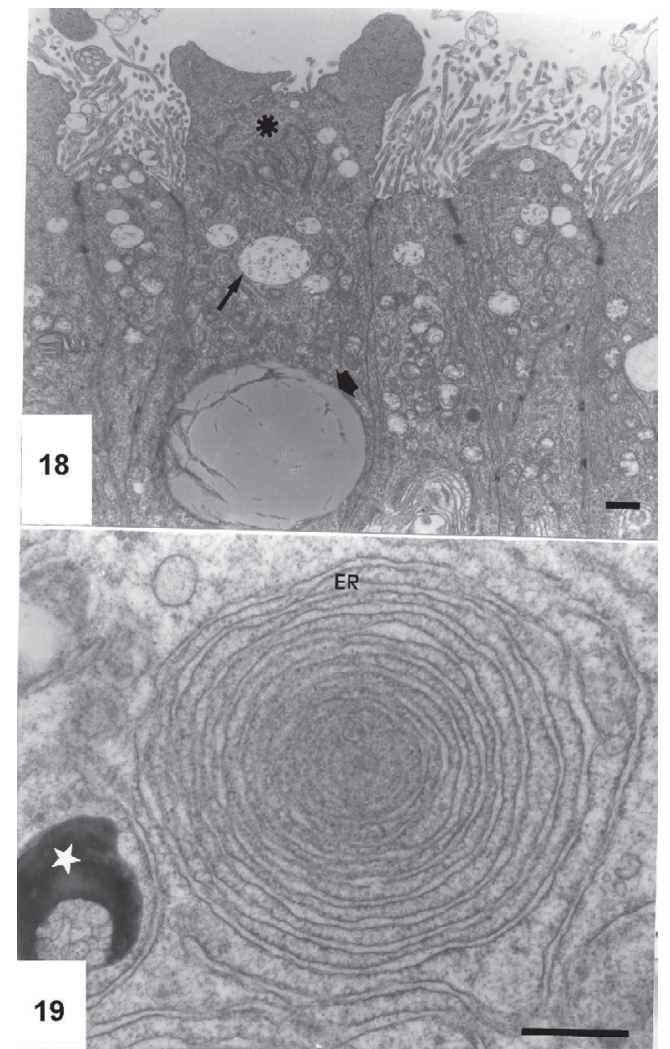

Figuras 18-19 - Citoplasma supranuclear e apical de células $P$ da cauda epididimária mostrando expansão citoplasmática apical (roseta) com aparelho endocitótico apical (seta pequena) e grande inclusão lipídica (seta espessa) em 20. Em 21, RER circunferencial (ER) com lamelas concêntricas ao nível do citoplasma infranuclear de célula $P$ com um lisossomo (estrela) adjacente. Bar $=1 \mu \mathrm{m}$ em 20; Bar $=0,5 \mu \mathrm{m}$ em 21

\section{Discussão}

O citoplasma supranuclear das células principais $(\mathrm{P})$ do ducto epididimário de paca foi caracterizado pelo desenvolvimento marcante do RER, em todas as regiões do ducto, apresentando cisternas lamelares longas, retilíneas, curvílineas e com disposição concêntrica, havendo também cisternas muito dilatadas e com características vesiculares. Cisternas com aparência vesicular, presentes principalmente nas células principais do epidídimo de paca, e de outros mamíferos ${ }^{5}$, foram identificadas como cisternas dilatadas do RE, que têm poucos ribossomos aderidos ${ }^{6}$, talvez tendo uma possível implicação na secreção de proteínas ${ }^{18}$.

A quantidade elevada de ribossomos aderidos às lamelas do RE, ou de polissomos adjacentes, presentes no citoplasma supranuclear de células $P$, expressaria elevada capacidade de síntese protéica ${ }^{9}$, cuja secreção deve ocorrer no SI de paca, como Nicander e Malmqvist ${ }^{19}$ sugeriram para o SI de outros mamíferos. Por outro lado, síntese e secreção protéica, poderiam ocorrer, também, em outras regiões do epidídimo de paca, como no corpo epididimal em que o RER é também proeminente. Para efeitos comparativos, há descrição na literatura quanto às diferenças regionais de secreção de proteínas no epidídimo de rato. ${ }^{5,20}$

A configuração geral do RER no citoplasma supranuclear de células $\mathrm{P}$, que foi observada principalmente no segmento inicial do epidídimo de paca, mostrou lamelas longas associadas aos dictiossomos do Golgi e vesículas revestidas, pequenas e densas, presentes no citoplasma adjacente a estas organelas. A associação entre o RER e os sáculos do Golgi, bem como a presença de vesículas densas adjacentes, poderia estar relacionada, também, à síntese e secreção de glicoproteínas pelas células $\mathrm{P}$ epididimais, como se caracterizou no epidídimo do camundongo Suíço. 2,3,4

Aparentemente, proteínas, secretadas pelo RER de células epididimárias, poderiam ser liberadas diretamente no lúmen epididimário. ${ }^{18}$ Por outro lado, a secreção de proteínas passaria, diretamente, através do aparelho de Golgi, antes de ser liberada no lúmen tubular. ${ }^{21}$ Porém, estudos autoradiográficos, com isótopos marcados, mostraram os grãos de prata inicialmente sobre o RER e sucessivamente sobre o aparelho de Golgi; superfície celular apical e lúmen tubular. ${ }^{1,2,6}$

O exato mecanismo de transporte de proteínas, ou seja, a natureza do carreador de macromoléculas secretadas, desde a face trans do Golgi até a superfície celular em células epiteliais epididimárias, não estaria ainda claramente definido ${ }^{6}$. Sugeriu-se a 
eventual participação de vesículas pálidas de superfície lisa, adjacentes ao Golgi, no transporte de proteínas secretadas ${ }^{5}$, ou seriam as pequenas vesículas, revestidas e densas, as responsáveis por este processo ${ }^{2,5}$. Com base em nossas observações, tende-se a concordar com a última interpretação, reservando-se às vesículas pálidas, e não revestidas, aparentemente, uma participação mais efetiva no aparelho endocitótico de células P.,

Outra característica marcante de células $P$, presentes no corpo e na cauda epididimais de paca, foi a observação de lamelas circunferenciais do RER, concêntricas e paralelas entre si, que foram observadas ao níveis citoplasmáticos perinuclear e infranuclear, respectivamente. Estas lamelas delimitavam um espaço do conteúdo citoplasmático contendo mitocôndrias, polissomos e grânulos eletrondensos, circunscritos por vesículas ou isolados, sugerindo também síntese de material protéico. De modo comparativo, a ocorrência de RER circunferencial, com material eletrondenso, diretamente relacionado, fora caracterizada em células principais do epidídimo do porco doméstico $^{22}$, sendo sugeridos processos de síntese e deportação de material proteináceo pelas células enfocadas ${ }^{23}$.

Atividades de endocitose de fase fluida (ou pinocitose), e de endocitose adsortiva (ou fagocitose) ${ }^{24}$ foram semelhantes às que se caracterizaram em células $\mathrm{P}$ do epidídimo de rato ${ }^{6,7,8}$, e em células de Sertoli de mamíferos ${ }^{24}$. Esse mesmo tipo de atividade foi evidenciada nos citoplasma supranuclear e apical de células $\mathrm{P}$ de todas as regiões epididimárias de paca. As estruturas envolvidas nesta atividade aparentavam ser as vesículas revestidas e as vesículas de superfície lisa, com diferentes formas e dimensões, e conteúdo predominantemente claro; os endossomos, corpos multivesiculares pálidos e densos e os lisossomos ${ }^{17}$

Os primeiros passos do processo de endocitose foram caracterizados pela presença de cavéolas, formadas apicalmente entre os microvilos, que se fecham e se internalizam como pequenas vesículas revestidas, no citoplasma apical, seguindo padrão anteriormente descrito. ${ }^{25}$ Conforme descrições anteriormente citadas, seguem-se as demais estruturas subcelulares interrelacionadas ao processo endocitótico.

$\mathrm{Na}$ parte proximal do epidídimo de paca notou-se a ocorrência de corpos multivesiculares, com conteúdo complexo, aparentemente, suportando a ocorrência de endocitose adsortiva, enfocada por Hermo, Oko e Morales ${ }^{6}$, no epidídimo de rato, ou talvez tendo relação com a ocorrência de processos lisossomais de digestões autofágica ou heterofágica. Além disso, ao nível do citoplasma apical e supranuclear de algumas células $\mathrm{P}$, em todas as regiões epididimárias, bem como nas células claras presentes somente na cauda epididimal, de paca, a presença das estruturas subcelulares integrantes de processos endocitóticos, foram tipicamente caracterizadas, seguindo modelos anteriormente propostos para esta atividade funcional. $5,6,26$

Quanto à ocorrência de expansões citoplasmáticas apicais, em células $\mathrm{P}$ no epitélio da cauda epididimária de paca, sendo que algumas delas eram extruídas para o lúmen epididimário, talvez pudessem ser caracterizadas como secreção apócrina, conforme descrições similares feitas em células principais do epidídimo de gato ${ }^{14}$, e em células claras epididimais do porco doméstico ${ }^{22}$. Porém, foram feitas também sugestões de que as expansões apicais (protrusões citoplasmáticas), seriam meros artefatos de fixação ${ }^{13}$, ou estruturas inertes e sem significado funcional marcante ${ }^{12}$. Referente à presença de inclusões lipídicas, presentes no citoplasma supranuclear de algumas células $\mathrm{P}$, talvez, representariam um reserva funcional, uma vez que normalmente teem sido notadas no citoplasma de células epididimárias. ${ }^{5,6,21}$

\section{Agradecimentos}

Este trabalho teve apoio financeiro parcial da FAPESP - São Paulo, SP (Processo 
01/14984-5), e contou com o serviço

Microscopia Eletrônica da UNESP, Campus

técnico prestado pelo Centro de de Botucatu, SP, Brasil.

\section{Regional ultra structural features of principal cells from the epididymal epithelium lining of Agouti paca}

\section{Abstract}

The principal (P) cells of epididymidis surface epithelium of Agouti paca were related to processes of adsorptive endocytosis and phasefluid endocytosis, as well as protein secretion apparently also occur. These findings had been proposed on the base the cytoplasmic ultrastructural features of P cells in which were seen an expressive number of vesicles with several shapes, sizes and internalized content occurring also smaller pits and pale small vesicles located next to the apical brush border of microvilli. Moreover, occurred coated vesicles, smooth surface vesicles and great vesicles; multivesicular bodies, endosomes and lysosomes mainly viewed on supranuclear and apical positions. Presence of an appocrine secretory pathway was characterized in P cells through the occurrence of apical cytoplasmic expansions, protruding into the ducts epididymidis luminal compartment.
Key words:

Epididymidis epithelium. Principal cells. Fine structure. Agouti paca.

\section{Referências}

1 FLICKINGER, C. J. Synthesis, transport and secretion of protein in the initial segment of the mouse epididymis as studied by electron microscope radiaoutography. Biology of Reproduction, v. 20, p. 1015-1030, 1979

2 FLICKINGER, C. J. Regional diferences in synthesis, intracellular transport, and secretion of protein in the mouse epididymis. Biology of Reproduction, v. 25, p. 871-883, 1981.

3 FLICKINGER, C. J. Synthesis and secretion of glycoprotein by the epididymal epithelium. Archives of Andrology, v. 4, p. 157-161, 1983.

4 FLICKINGER, C. J. Autoradiographic analysis of the secretory pathway for glycoprotein in principal cells of the mouse epididymis exposed to $\mathrm{H}^{3}$-fucose. Biology of Reproduction, v. 32, p. 377-389, 1985.

5 ROBAIRE, B.; HERMO, L. Efferent ducts, epididymis, and vas deferens structure, functions, and their regulation. In: KNOBIL, E.; NEILL, J.D. (Ed.). The physiology of reproduction. New York: Raven Press, 1988. chap. 23, p. 999-1080.

6 HERMO, L.; OKO, R.; MORALES, C. Secretion and endocytosis in the male reproductive tract: a role in sperm maturation. International Review of Cytology, v. 154 , p. $105,119,189,1994$.

7 SERRE, V.; ROBAIRE, B. Segment-specific morphological changes in aging brown Norway rat epididymis. Biology of Reproduction, v. 58, p. 497513, 1998.

8 DOMENICONI, R. F.; ORSI, A. M.; BEU, C. C. L.;
FELISBINO, S. L. Morphological features of the epididymal epithelium of gerbil, Meriones unguiculatus. Tissue and Cell, v. 39, p. 47-57, 2007.

9 LIU, H.-W.; SHANG, S.-T.; CHAO, C.-F.; MULLER, C. The secretion of two sperm maturation-related glycoproteins in BALB/c mouse epididymis. Cell Tissue Research, v. 265, p. 409-414, 1991.

10 ORSI, A. M.; MATHEUS, S. M. M.; GREGORIO, E. A.; BEU, C. C. L. Morphological investigations of the surface of ductuli efferentes of black isogenic mouse (Mus musculus). Anatomia, Histologia, Embryologia, v. 27 , p. 215-218, 1989.

11 BERNARD, R. T. F. The occurrence of spermiophagy under natural conditions in the cauda epididymis of the Cape horseshoe bat (Rhinolophus capensis). Journal of Reproduction and Fertilility, v. 71, p. 539-543, 1984

12 VENDRELY, E.; DADOUNE, J. P. Quantitative ultra structural analysis of the principal cells in the human epididymis. Reproduction Nutrition and Development, v. 28 , p. $125-135,1988$.

13 STOFFEL, M.; FRIESS, A. E.; KHOLER, T. Efferent ductules of the boar: a morphological study. Acta Anatomica, Basel, v. 142, p. 272-280, 1991.

14 MORALES, A.; CAVICCHIA, J. C. Release of cytoplasmic apical protrusions from principal cells of the cat epididymis: a electron microscopic study. Tissue and Cell, v. 23, p. 505-513, 1991.

15 MONDOLFI, E. La laca o paca: defensa de la naturaleza. Caracas, v. 2, n. 5, p. 4-16, 1972.

16 EISENBERG, J. F. Order rodentia. In: Mammals of the neotropics: the northern neotropics. Chicago: The 
University of Chicago Press, 1989. v. 1, p. 395-397.

17 HESS, R. A. The efferent ducts: structure and function. In: ROBAIRE, B.; HINTON, B. T. (Ed.). The epididymis from molecules to clinical practice. New York: Kluwer Academic, 2002. v. 1, p. 49-80

18 HOFFER, A. P.; HAMILTON, D. W.; FAWCETT, D. $W$. The ultra structure of the principal cells and intraepithelial leucocytes in the initial segment of the rat epididymis. Anatomical Record, v. 175, p. 169 202, 1973.

19 NICANDER, L.; MALMQVIST, M. Ultrastructural observations suggesting merocrine secretion in the initial segment of the mammalian epididymis. Cell Tissue Research, v. 184, p. 487-490, 1977.

20 BROOKS, D. E. Secretion of proteins and glycoproteins by the rat epididymis: regional differences, androgen-dependence, and effects of protease inhibitors, procaine and tunicamycin. Biology of Reproduction v. 25, p. 1099-1117, 1981.

21 GUNN, S. A., GOULD, T. C. Vasculature of the testes an adnexa. In: GREEP, R.O.; ASTWOOD, E.B.

(Ed.). Handbook of physiology. Washington D. C. American Physiology Society, 1975. v. 5, Sect. 7, p.
117-142.

22 BRIZ, M.; BONET, S.; FRADERA, A. A morphologic study of the ducts of the epididymis of Sus domesticus. Journal of Morphology, v. 215, p. 183193, 1993.

23 ORSI, A. M.; MATHEUS, S. M. M.; STEFANINI, M. A.; VICENTINI, C. A.; RIBEIRO, A. A. C. M.; MIGLINO, $M$. A. Fine structure of the lining epithelium of the ductus deferens in gerbil: a segmental study. Brazilian Journal of Morphological Sciences, v. 16, p. 189-195, 1999.

24 CLERMONT, Y. Introduction to the sertoli cell. In: RUSSEL, L. D.; GRISWOLD, M. D. (Ed.). The sertoli cell. Clear water, FL: Cache Rivers Press, 1993. 800 p.

25 GOLDSTEIN, J. L.; ANDERSON, R. G. W.; BROWN; M. S. Coated pits, coated vesicles and receptor mediated endocytosis. Nature, London, v. 279, p. 679-685, 1979.

26 HERMO, L.; BARIN, K.; ROBAIRE, B. Structural differentiation of the epithelial cells of the testicular excurrent duct system of rats, during postnatal development. Anatomical Record, v. 233, p. 205-228, 1992. 